\title{
Exploring the meaning of pro-vaccine activism across two countries
}

\section{Samantha Vanderslott}

Oxford Vaccine Group and \& Oxford Martin School, University of Oxford, 34 Broad St, Oxford, OX1 2BD, UK. samantha.vanderslott@paediatrics.ox.ac.uk

Working paper version. Later published in Social Science and Medicine, Feb 2019, 222, 5966: https://www.sciencedirect.com/science/article/pii/S0277953618307160?dgcid=author

\section{Abstract}

While vaccine-critical activism has been widely documented and discussed, comparatively little has been said about the concerted response of pro-vaccine activists defending the majority view. This paper explores two case studies of pro-vaccine activism in Australia and the United States (US). It shows how pro-vaccine views and behaviours can take varying forms due to different aims and methods of engagement - oppositional counteractivities in favour of vaccination in Australia, and issue-based advocacy as part of a political alliance in the US. The focus in Australia comes from a pro-science stance and includes 'skeptics' against pseudoscience directly opposing vaccine-critical groups. In the US, the focus takes the form of an issue-specific campaign that has arisen from existing pro-vaccine parent blogs and discussion groups pushing for policy change rather than public confrontation. These case studies exemplify how pro-vaccine activism can take varying forms of either reinforcing the mainstream view or countering digression from it. Drawing on qualitative research, this paper aims to examine the types of practices and strategies employed by activists to voice their support of vaccination, and discusses the means, messages, and motivations of pro-vaccine activism. It ends with an argument for why a study - of public support for in addition to studying public opposition to vaccination - can help to better understand vaccination views and behaviours. These findings have wider implications for the study of counter-activism and the polarisation of civil society groups. 
Keywords: Australia; United States; pro-vaccine; activism; civil society; social movement; vaccination policy; anti-vaccine

\section{Introduction}

"When Jonas Salk invented the polio vaccine, he was a hero - and I'm a terrorist?"

(Paul Offit quoted in McNeil, 2009)

Paul Offit is an American paediatrician and co-inventor of a rotavirus vaccine licensed in 2006. In the above quote, Offit reflects on how he is vilified, while Jonas Salk, the inventor of the first polio vaccine, was a national hero celebrated for his scientific achievement. Offit speaks out in support of vaccination through mainstream media and popular science books. In response, he is labelled a terrorist — the anti-hero who threatens individual liberties through violence and fear - and is a regular target of online hate mail and death threats (Smallwood, 2008). Offit's treatment is indicative of how a scientist who developed a vaccine and espouses pro-vaccine views can be viewed as a negative force. However, the comparison to Salk shows how, at various times, places, and for certain diseases, vaccination has been viewed, demanded, and supported very positively.

When Salk's polio vaccine was successfully trialled in the 1950s: "Church bells tolled, horns honked, and sirens rang out as the nation rejoiced" (Jacobs, 2015, p. 166). The mid-century was a "golden decade of vaccines, when immunization became a 'sacrament' that received only rare public questioning" (Johnston, 2004, p. 244). The fear and devastation of polio saw parents lining up in the streets to have their children vaccinated.

Despite such outward displays of support, a common view on one hand is of opposition and scepticism by vaccinating populations, further amplified by anti-vaccination enclaves and 'echo chambers' online (Faasse et al., 2016; Grant et al., 2015). On the other hand, pro-vaccine stories are not as widely reported, as Spier describes, "...the successful prevention of disease in tens of millions of individuals is virtually ignored [emphasis original]" (2001, S83). Still, pro- 
vaccine stories and associated activist campaigns have reached some prominence. It is these campaigns that I bring attention to.

As Moskalenko and McCauley (2009) have argued, there is a scale of involvement in political mobilisation that makes the distinction between activeness and collectiveness in pro-vaccine activity important. By activeness I refer to the level of direct action taken in support of vaccination and collectiveness as to whether this is done in a group and for collective ideals. Thus, this paper is concerned with activism to promote vaccination organised at citizen level, going beyond dominant social practices endorsed by authorities. I will use the term pro-vaccine activism to refer to any citizen-led promotion of vaccination uptake that is proactive in seeking change. Typically, government and public health institutions are those that address and counter anti-vaccination views (Dubé et al., 2013). Instead of activism seeking change to the mainstream, pro-vaccine activism reinforces the mainstream and counters digression from it.

I will use two case studies as prominent examples of overt pro-vaccine support. In both cases, activism is mostly directed at those opposed to vaccination, or at under-vaccinating demographics (Dubé et al., 2013; Karafillakis et al., 2017; Yaqub et al., 2014). This paper will explore the meaning of pro-vaccine activism pursued by two groups - 'Vaccine California' in the US and 'Stop the AVN' (SAVN) in Australia - and how their pro-vaccine activities are creating an impact. I draw upon qualitative research of 25 semi-structured interviews with campaigners, health professionals, and policy officials, as well as a documentary analysis of web materials and online discussions related to the pro-vaccine activist groups.

My key claim in this paper is that pro-vaccine activism can take two distinct forms: collectivelyminded, parent-based groups that are fostered via mainstream political actors; or pro-science and anti-pseudoscience movements that directly oppose anti-vaccination views and activity. As Nadja Durbach (2004) has shown through her historical analysis of vaccination views in $19^{\text {th }}$ century England, vaccine issues are linked to wider political and social debates. Vaccine views and behaviours, therefore, are reflective of overlapping social, cultural, and political identities that cannot simply be distilled into an unproblematised binary distinction of either 'pro' or 'anti'. Section 1 begins by addressing the binary approaches to vaccination activism, both theoretically and empirically, drawing upon social movement literature. Section 2 covers the 
methods used to develop the two case studies, through interviews with key protagonists and analysis of web materials and online discussions. Section 3 presents the case studies of Vaccinate California in the US and SAVN in Australia, comparing the aims and methods of engagement employed. Section 4 discusses the mobilisation of pro-vaccine activism through the means, messages, and motivations of pro-vaccine activists, before concluding in Section 5 with recommendations for future research and policy interpretations.

\section{Beyond binary approaches to vaccine activism}

Pro-vaccine activism can be set against the sociological literature of new social movements and, more specifically, of the health and social movements that have emerged since the 1960s. Social movements are commonly defined as intentional and sustained efforts to bring about or delay social change, usually outside of institutions endorsed by authority (Ritzer, 2016). Additional understandings of social movements are of an organised and collective activity (Wilson, 1973) and the sharing of a common culture (McCarthy and Zald, 1977). 'New' social movements focus on public and government relations, often taking the form of resisting control and challenging authority (Brown and Zavestoski, 2004) and concern for "identity, individuality and control of one's body", bringing those issues to wider acceptance by the public (Mclnerney, 2000 , p. 138). Pro-vaccine activists, in comparison, tend to emphasise group identification, collectiveness, and public control, without particular concern for popular acceptance.

Pro-vaccine activism stands apart from the type of health social movement typically studied. Their activism stops short of being a fully-fledged social movement and does not want to bring an unknown or unaccepted identity into the public domain, but rather reasserts an accepted view in line with government authority and control. What is valuable to take from this concept of health social movements, as Phil Brown and colleagues (2004) have explored, is how identity is politicised and made collective. Identities are formed through the experience of the health issue in question, but also the political position this produces. Thus, the resulting identity is selffashioned through the combination of biomedical and social worlds, with biomedical authority still present; but the individual is not simply a passive receptor. As Katie Attwell and David Smith 
argue, "...the decision to vaccinate or not is an inherently social one, and not a matter of individual rationality" (2017, p. 183).

While being a heterogeneous collective, I argue that pro-vaccine activists share a social 'health issue identity', as do those critical of vaccination who have attracted the most attention in recent years. In this paper, I use the term 'vaccine critics', to denote those critical of vaccination but not necessarily opposing all vaccines, and use 'anti-vaccination' for a wholesale rejection of vaccination (and where used by others). I do not apply the term 'movement', as I am concentrating on individual activist group activity. In any case, the term is problematic as it is difficult to demarcate from other types of organisational descriptors (Blume, 2006), and a distinction must be made as to whether a movement is consistently, marginally, or occasionally vaccine-critical (Ward, 2016).

Concerning the terms 'pro' and 'anti' themselves, using the labels without further distinction negates the complexity of opinions and also gives charge to the idea of an even split between two ideologically opposed camps (Ellerton, 2014; Thomas et al., 2017). The pro-vaccine (and pro-vaxxer) categorisation is commonly used in the media, policy, and academia, but it has not been problematised to the extent that anti-vaccine (and anti-vaxxer) has. Although anti-vaxxers tend to be seen as personifying of the problem of vaccination acceptance (Kata, 2012; Venkatraman et al., 2015), some variation within is recognised. For example, Pru HobsonWest's distinction (2007) between "radicals" who reject vaccines outright and "reformists" looking to change vaccination policy. Others have identified a large number of parents to be best described as "anxious" (Leach and Fairhead, 2007) or "hesitant", where parents delay vaccination or pick and choose vaccine schedules (Dubé et al., 2013; Yaqub et al., 2014). However, my aim in concentrating on pro-vaccine activists is an attempt to highlight vaccine support and provide further distinction about what this means from a civil society perspective.

Pro-vaccine views did receive some scholarly attention in the 1990s. Anthropologist Mark Nichter (1995) originally distinguished between "active demand" in an informed public recognising the need and benefit of vaccination, and "passive acceptance" of the public yielding to health authority recommendations and societal pressure. The active characterisation of Nichter is still relevant, as there are parents who both actively demand or actively resist 
vaccination. Researchers have directed little attention to what motivates or influences overt civil society demand and support for vaccination, either during times of opposition to vaccination or stable periods of vaccination uptake.

Indeed, the 'problem publics' are the vaccine critics, and this is why they receive the most attention in how allegedly false beliefs can persist while being in the minority. Unlike the vaccine critics, pro-vaccine activists are not problematic, and are hence overlooked. However, they can offer an insight into unfolding vaccination debates and reactions to anti-vaccination ideas. This is why I refer to such an account as a 'symmetrical' analysis in the sense popularised by David Bloor (1991). He argued that, when analysing a scientific controversy, it is important for each side of a competing knowledge claim to be treated equally through social analysis and not as being either true or false. Inspired by this idea of symmetry, I analyse a side of a debate not usually observed because it is perceived as being on the 'right' side of scientific understanding. Such an approach is connected to Bloorian symmetry by not assuming pro-vaccine views and behaviours are the correct knowledge, thus not needing enquiry.

\section{Methods}

I use two case studies as highly visible examples of pro-vaccine activism: Vaccinate California in the US and Stop the AVN (SAVN) in Australia, gathering information on their activities over eight months from June 2017 to February 2018 (university ethical approval: R50658/RE001). To develop a multi-layered depiction of the formation and strategies of both groups, I undertook 25 semi-structured interviews. As I limited the scope of the study to a comparison of two activist groups, this approach was preferred to survey data.

The method for selecting interviewees began with a core set of the founders, members and supporters of both groups, followed by snowball sampling of a second set of actors in their immediate networks (Appendix 1 shows interviews by organisation type). For the Vaccinate California case study, I undertook nine interviews with founders, policy officials, academics, and NGO workers from organisations with vaccination promotion missions. Eight interviews were with local health authorities in California, where it was logistically straightforward to conduct face-to-face interviews. For the SAVN case study, I undertook eight interviews with 
SAVN members based in Australia, as well as health authorities, academics, and groups influenced by SAVN (which included New Zealand). Due to geographic distance between interviewees, these interviews took place via video-call. Video-call had the advantage that interviewees expressed themselves more honestly in a relaxed setting, but it was harder to observe physical cues.

Throughout the enquiry, I also interviewed five academics involved with the groups, to in order to gain perspective on how those researching controversial topics can be drawn into the debate (see Scott et al., 1990). The academics interviewed all reported hostile behaviour from whichever set of actors they were critical of, a tendency to which I can relate. I have experienced negative comments to public-facing articles, including discouraging emails, from vaccine critics and supporters (presumably for not taking a clear 'side').

The interviews averaged 70 minutes and I continued some email correspondence for sharing material and for further discussion. Interviewees signed a formal consent form with an anonymisation option. Many public health workers were anonymised, not wanting personal views to be representative of their organisation. The questions I posed were pre-set yet openended, with some flexibility to adapt by interviewee. Questions centred around how interviewees viewed themselves as being 'pro-vaccine'; what drove such views; the internal structure and history of their organisation, aims and activities; and how that related to other groups and institutions, broader societal implications of their actions, and the regional/country context. I was aware that the pro-vaccine activists could find it socially desirable to tone down views (Kuran, 1995). This came across through dismissiveness to towards opposing views (i.e. "it is not worth trying to change their minds"). All interviews were recorded and fully transcribed (Appendix 2).

After completing the interviews, I undertook a documentary analysis to identify 'storylines' of policy processes, public engagement over time, and how actors developed versions of a story (Hajer, 2009). The storylines I became aware of included the 'triggers' for their actions - which was the 2015 measles outbreak for Vaccinate California and the treatment of parents (the 
McCafferys) in the case of SAVN. I drew upon a variety of documentary material including the activist groups' materials (websites, social media sites, and court transcripts), the state archives on Senate Bill SB 277 to ban non-medical exemptions to vaccination, materials obtained through interviews (reports and presentations), media accounts accessed through the LexisNexis database, and newspaper archives (using keyword searches of: Vaccinate California, SB 277, SAVN, AVN). To interpret the results, I organised and coded the material under themes: (1) the origins of the groups and reasons for forming (external events, values, and norms); (2) main motivations (what they hoped to achieve and measurement of success); (3) situation in the policy and media context; (4) comparisons to other group/country contexts. I analysed the results with the assistance of NVivo software, to develop a grounded theory of the formation and strategies of the groups.

The methodological limitations were largely due to observing people and events outside the country context and not in real time. As a result, some contextual country points may have been missed, including related discussions happening at that time. The selection of two cases is also limited in not depicting pro-vaccine activism widely, and this is an avenue for further research proposed in the conclusion.

\section{Case studies: 'Vaccinate California' and 'Stop the}

\section{AVN' (SAVN)}

In Australia, pro-vaccine activism has focused on resisting a vaccine-critical group established in 1994 by parent Meryl Dorey, originally called the 'Australian Vaccination Network', and now renamed the Australian Vaccination-skeptics Network (AVN). Stop the AVN (SAVN) was formed in 2009 with the explicit aim to shut down the AVN. Through direct confrontation, SAVN have dramatically limited AVN activities and are likely to continue opposing AVN and similar groups and individuals. In comparison, the US has witnessed a less confrontational, more issue-specific campaign to boost child vaccination in California. The focus was enacting a particular policy (California Senate Bill SB 277) and legal change, rather than wider societal or ideational change, and its activities more or less ceased after the bill was successfully passed. 


\subsection{Vaccinate California: reacting to measles in Disneyland}

The 2015 Disneyland measles outbreak in Orange County, California, brought the issue of vaccination to the forefront in the state. The major disruption caused is described by Law professor Dorit Reiss: “...cases from the measles Disneyland outbreak went to $170 \ldots$ And we exported it to 16 additional states, to Mexico, and to Canada. California would rather be known as an exporter of movies and avocado than of measles" (interview with author, 2017).

Prior to 2015, California had been called an "epicenter of vaccine refusal" (Dr Blaise Congeni, quoted in Khimm, 2010). Journalist Tara Haelle describes how this created a unique situation with pro-vaccine parents spurred into action by a "direct threat to their children" (Milken Institute School of Public Health Blog, 2015). Doctors reported how some parents did not want to be in the same waiting room as unvaccinated families, a change in tone described by this father: "Before, I thought, 'If you think your child will become autistic, fine'. But now they're pushing their beliefs on everybody, and I feel differently" (Healy and Paulson, 2015). Reiss also spoke of her experience as a social media commentator: "After the Disneyland outbreak, you suddenly saw a dramatic growth in people speaking on the pro-vaccine side. And many of them were people that never were active before" (interview with author, 2017).

\subsection{Locating the activists with four moms}

In California, pro-vaccine groups have existed for some time. California, like all other states, has an 'immunization coalition' comprised of community partners interested in improving vaccination provision and uptake. There are parent-led pro-vaccine groups present on a national level (including 'Voices for Vaccines' and 'Moms Who Vax'). A 'deficit model of public understanding', where a lack of information about vaccination fuels incorrect and negative views, has been a driving approach but there is growing recognition that this is flawed (Leach and Fairhead, 2007). Simply supplying better and more information about vaccines is an insufficient strategy and more participatory engagement is needed. The way that publics come to form a view on vaccination is changing and according to Christine Vara, editor of the 'Vaccinate Your Family' Facebook page and the blog A Shot of Prevention', social media is playing a bigger role: "Things were being said and there was nobody really there to say, 'Whoa, wait a minute, that's not really how it is"' (interview with author, 2017). These groups aim to 
reach out to vaccine-hesitant parents and convince them to vaccinate or support healthcare workers by engaging in conversations with parents through the use of vaccination stories and educational materials. The effort to increase vaccination rates is largely limited to discussion on vaccine facts.

Some parents thought the situation needed solving through legislation. Californian State Senators Dr Richard Pan and Ben Allen authored Senate Bill SB 277 to remove non-medical exemptions for vaccination requirements. Vaccination is mandatory in all US states to attend public school, state-licensed childcare, family day care and developmental centres, along with some private institutions (Orenstein and Hinman, 1999). However, all states allow for medical exemptions, and two at the time (Mississippi and West Virginia) did not allow for any other types of exemptions (i.e. on philosophical, personal, or religious grounds).

The Senators were already supportive figures. Pan, a paediatrician, had experienced a measles outbreak in Philadelphia and passed Assembly Bill AB 2109 in 2012 to make religious and philosophical exemptions harder to obtain, while Allen's father was a polio survivor. Both wanted to take action but felt it was impossible without a strong parental push to convince the wider public and Senate; a constituency needed to be built. The Senators made calls to parent groups on social media, to which four mothers responded to, and Vaccinate California was formed in 2015 to co-sponsor SB 277 (Vaccinate California, 2017).

The Vaccinate California co-founders are four closely connected mothers: full-time mother and ex-lawyer Leah Russin, designer Hannah Nery, technology and finance analyst Renne Diresta, and full-time mother and former public relations worker Jennifer Wonnacott — all with skillsets contributing to an aspect of the group's activities (Vaccinate California, 2017). They went on to recruit 20-30 other supporters, assigning tasks to each depending on their strengths. Vaccinate California did not engage directly with vaccine-hesitant or vaccine-refusing parents, who were directed to other resources. Their baseline position was: "The vast majority agree with vaccination. They vaccinate and go about their business" (Russin, interview with author, 2017). The mission was to turn "quiet pro-vaccine parents" into "noisy pro-vaccine parents" and 
generate an alternative to the loud anti-vaxxer as described by co-founder Renee DiResta: "The anti-vaxx movement is well-organized, it's well-funded, and it's media-savvy... Legislators are only hearing from the passionate minority" (DiResta, 2017).

Vaccinate California made a point of not arguing about vaccine science, autism, or conspiracy theories, but responded to discussion about parental rights and choice. They argued that immuno-compromised children's right to health and education trumps the right of parents to ignore science, as Russin's testimony before the Senate Judiciary Committee demonstrates: "We have the right not to have our children endangered at school by preventable disease. There are parents who disagree with me... But their decision not only jeopardizes the health and safety of their children, it puts my child at risk and that is unfair" (Whatthefolly, 2015).

Vaccinate California mainly put forward their views through Facebook, bringing together dozens of pro-vaccine parenting groups. Russin found that many had legitimate questions (e.g. about schedules) but were "jumped on" by anti-vaxxers before anyone else could answer. Twitter, according to Russin, attracted the more "tin-foil-hat types" not worth engagement. Mainstream media coverage, however, proved problematic: "Telling the story of Vaccinate California is not as interesting as an anti-vaxx one... the news media think they are repeating fact, but they write about conflict" (Russin, interview with author, 2017). Through their online presence, they collected 32,770 signatures supporting the Senate Bill, which they delivered to the Senators and was supported by figures such as a six-year old Californian boy suffering from leukaemia named Rhett, who made a personal appeal (Change.org, 2017). Gaining traction through Facebook and e-petitions, Vaccinate California provided parental support and legitimacy to the Senate Bill. By 2016, SB 277 came into force, removing non-medical exemptions in California. However, conflict is not dispelled completely, as protests and lawsuits continue from those opposing the bill (Sisson, 2016).

\subsection{SAVN: reacting to the treatment of the McCaffery family}

Vaccinate California addressed falling vaccination rates and consequent disease outbreak, with a solution sought primarily through policy and legal means. In Australia, by contrast, 'Stop the 
AVN' (SAVN) were reacting to the treatment of a bereaved family by a vaccine-critical group and saw the shutdown of that particular group as its main goal.

The event that sparked SAVN was the death of four-week-old Dana McCaffery due to pertussis (whooping cough). The day before the funeral, the media reported that the president of the AVN, Meryl Dorey, had tried to obtain Dana's medical records (Hansen, 2013a). Although Dorey contends she did not (No Compulsory Vaccination, 2017), she does assert she wanted proof of death from pertussis, and questioned the finger-pointing at those opposed to vaccination: "To my mind, an entire community of conscientious objectors were being victimised by the government and the media and being blamed for the death of a child who was too young to be vaccinated" (Meryl Dorey, 2017).

The McCafferys established a website and Facebook page, telling Dana's story as an educational tool for vaccination (ibid.). They saw it as a community service in order to raise awareness of the importance of pertussis boosters (where an extra dose of the vaccine is received during pregnancy). They subsequently received a letter, including AVN pamphlets, to their home address, "telling them they should have just stayed at home and breastfed the baby" (Hansen, 2013a). Also, on the Australian national television programme 'ABC 7.30 Report', the McCafferys and Dorey appeared together speaking about pertussis vaccination. After it aired, Dorey encouraged her subscribers to complain to $A B C$ about the show's editing and posted on the McCafferys' website questioning vaccines. Andrew McDonald, a regular on AVN forums, even sent an email to the McCafferys claiming: "Dana passed away for different reasons than you claim" (Hansen, 2013a). SAVN was formed in late 2009 in a direct response to the AVN's treatment of the McCafferys.

\subsection{Locating the activists with like-minded skeptics}

'Australian Skeptics Inc. (ASI) is an organisation for "like-minded people to gather and become active... they address the whole range of quackery, which is everything from homeopaths through to psychics and water diviners" (McLeod, interview with author, 2017). These pseudoscience skeptics investigate and challenge paranormal claims, arguing their movement 
came about because scientists have not taken responsibility for countering anti-science views (Loxton, 2017).

A number of those on the ASI committee are involved with SAVN, although it was independently formed and has adopted a broad constituency, with 17,000 followers on Facebook (as of October 2018). One SAVN and ASI member, Rachael Dunlop, is a senior researcher at Brain Chemistry labs (Institute for Ethnomedicine, Wyoming, US). Known as 'Dr Rachie' in her pseudoscience skeptic work, she has published articles in the mainstream media supporting vaccination (Dunlop, 2013a, 2013b).

Other members of SAVN have less connection to pseudoscience skeptics. SAVN is unusual in its wide and varied membership. For example, philosophy lecturer Patrick Stokes recounts: "I started interacting with the SAVN Facebook page... and I wrote a piece for 'The Conversation'. That became quite popular and, through it, I ended up being sort of involved more and more within the administration of SAVN, and then some of its activism campaigns" (interview with author, 2017). Ken McLeod became involved following a career in air traffic control as a senior manager and, later, whistle blower: "I was used to whistle-blowing in political activism. I stimulated a couple of Senate enquiries and it just seemed a natural drift... my baby sister had polio. I was very young and so l'd seen what happens up close" (interview with author, 2017). Thus, McLeod had both a personal connection to the trauma of disease seen as being vaccinepreventable and ample experience in pushing policy change. He felt that outlining a social ill to the public was not enough and they "needed to do something" to stand out from other provaccine groups that focus on education and "just giving the facts" (interview with author, 2017). Facebook offered an initial forum to counter the AVN, followed by other online strategies, including a "Google bomb" (manipulating AVN Google searches to result in pro-vaccine websites, by giving those sites a high search rank).

Dunlop calls it "being proactive rather than reactive", to "prevent the passage of info from professional anti-vaccinationists to the public" by "those who profit from promulgating antivaccine ideas" (Rachael Dunlop, email correspondence, 2017). Thus, they aimed to "drive 
these people out of business" (Dunlop, interview with author, 2017). SAVN are keen to point out that this aim is justified because the AVN is not some typical non-profit parent group, but a for-profit endeavour seeking to make money off reading materials, talks, and donations.

SAVN have not only been active online, but also attempted to cut off AVN platforms and income sources by contacting the AVN's venue hosts and sponsors, pursuing legal action, and through policy means. Following a complaint, the Australian Office of Fair Trading deemed the name 'Australian Vaccination Network' as misleading and a detriment to the community, causing AVN to rename itself the Australian Vaccination-skeptics Network. The McCafferys also filed a formal complaint to the Health Care Complaints Commission (HCCC) for the AVN's spreading of misinformation: "The HCCC found against the AVN and issued a public warning about the group in July 2010. The AVN lost their charitable status as a result, but won it back after a NSW Supreme Court challenge ruled the HCCC did not have the jurisdiction" (Health Care Complaints Commission, 2014). The government quickly amended the relevant legislation and the public warning was reissued to cancel AVN's charity licence.

These outcomes indicate a supportive pro-vaccine environment in Australia. Heap believes that news outlets are less likely to adopt a 'false balance', raising the profile of minority views by allocating the same time and attention to both sides of the vaccine debate (interview with author, 2017). Politicians have also become more comfortable speaking in support of vaccination, and two recent policies - 'No jab, no pay', removing child benefit payments (and non-medical exemptions), and 'No jab, no play', restricting state day care - aim to curb falling vaccination rates (Beard et al, 2017). However, grassroots activists have been less directly involved in these policy changes, which have origins in their current form from a joint media campaign by Australian newspapers 'The Sunday Telegraph' and 'The Daily Telegraph' (Hansen, 2013b). Perhaps indicating journalistic policy origins, many local health officials I spoke with viewed these policies as populist and not particularly helpful long-term, further polarising the vaccination debate and hindering discussion between both sides (also see Leask and Danchin, 2017). Thus, there are other considerations that result from instituting coercive policy. 


\section{Discussion: the means, message, and motivation}

These case studies can be distinguished from other examples of vaccination views and behaviours by asking two questions: "What are the reasons for and impact sought by this provaccine activity?" and "What are the wider political, social, and moral arguments conveyed?" To address these, I will consider the means, message, and motivation of pro-vaccine activism and the importance of taking a country-level view.

\section{The means}

Firstly, the means of pro-vaccine activism in these cases have largely been online. Discursive battles between supporters and critics of vaccination increasingly take place in a virtual space, through social media and other online venues. This virtuality allows for networks to be created based on shared beliefs for narrow topics and gives organisers a resource-light means of sharing ideas and enabling discussion. Social media offers the means of putting forward opinions, helps to amplify views, and also provides an organising space for action. For provaccine supporters, this has helped turn a previously quiet and disparate constituency into an active support for vaccination.

However, as vaccination policy differs across countries, online activity does not take on a global shape and activism is shown to differ greatly in the two country case studies. In the US, vaccination is mandatory for public schools and day care (with exemptions), while in Australia this has not been the case (although it is beginning with day care). As opposed to Australia where activism can be very broad in influencing state policy, the legal entrenchment of vaccination in the US means the battle lines are drawn elsewhere. The US vaccine debate is played out in exemptions to vaccination - in a heightened way, across states. In Australia, persuasive routes using media influence are most common but increasingly more regulatory routes are employed such as withholding welfare payments and state childcare provision to those who do not vaccinate, and not allowing for any non-medical exemption. Against this backdrop, the activist groups take different means, but are both coercive in character: SAVN being coercive in their activities towards the AVN to shut them down, and Vaccinate California wanting to enact more coercive policies by tightening the vaccine exemption law. 


\section{The message}

Secondly, the message that each group has attempted to convey differs substantially and points towards sources of cross-country differences. Framing a particular message is used to both galvanize collective action (Benford, 1993) and to set boundaries for that action (Silver, 1997). The message of Vaccinate California falls under an education and safety frame. The 'safe school' argument overrides the right for choice in public spaces and derives from a collective idea of parenting and care for children (at least in a minimal sense of not causing harm to other children). Such a parenting view: firstly, is connected to values upholding science, evidence, and state authority; and secondly, means that activists can disengage with directly opposing viewpoints and avoid explicitly addressing competing knowledge claims. Direct oppositional activity seen in Australia has been less prevalent in the US.

Public figures such as Paul Offit, while outspoken, do not make overtly confrontational attacks on vaccine critics. Offit is wary of taking any direct action aside from voicing his opinion. Similarly, on US-based online forums, comedy and satire are used as a tactic to demean and ridicule vaccine critics (e.g. a Facebook group called 'Refutations to Anti-Vaccine Memes' using humorous memes to counter vaccine critics, and the blog 'Respectful Insolence' by US surgeon David Gorski, refuting pseudoscience claims). The attacks made are often identity-based, but do not directly attempt to disrupt the activities of vaccine critics. SAVN, by contrast, directly opposes vaccine-critics, undermining them financially, legally, and as a credible knowledge source.

Likewise, while Vaccinate California played a crucial role as the parental mandate to pass SB 277 , there are limits to this type of activism, as no equivalent lobby exists nationally. I make this point not only to highlight the system of vaccination policy within US states but also the connection of political culture to opportunity structures for resource mobilisation (see Goodwin et al., 2003). In the US, the policy environment is not amenable for a group to directly counter vaccine critics, like in Australia. As Dunlop saw it, a group like SAVN could only really be successful in Australia and would not find a foothold in the US (interview with author, 2017). Not only would the scale of organisation and resources need to be greater to make rhetorical 
arguments. Such argumentation would need to stand up against freedom of speech, which is constitutionally enshrined, and individual choice often elevated as an ideal above 'big government', in ways that create difficulties for pursuing notions of the common good. Indeed, Reich frankly concludes in her 2016 book that Americans do not see community support benefiting them, rendering collective responsibilities irrelevant; although, as I have shown, a concept of collective parenting concerning public spaces does exist.

SAVN's message, by contrast, falls under a pro-science frame. Their stance is scientific, expertand evidence-based, and the opposition is 'loony', crank, and pseudoscientific. It is a broadbased constituency that can move away from the issue of parental autonomy over health decisions and the safety or risk judgements made. Upholding pro-science values is a bigger focus than a reiteration of the importance of vaccination itself, which is taken as given. The emotional intensity of grieving parents being under attack gives added moral legitimacy to the cause.

SAVN's moral indignation is combative, with little discussion or attempt at understanding inbetween. Such a position, according to two Australian academics, is detrimental. Public health academic Julie Leask is concerned about inhibiting constructive debate: "If we have an attitude of shutting down criticism, then we may have situations when we don't listen when we really need to" (Bramwell, 2014). Sociologist Brian Martin, meanwhile, is critical of methods used by SAVN to silence free speech and discredit individuals through "verbal abuse, harassment (especially via numerous complaints) and censorship" (2016, p. 27).

Even if SAVN do fit this description, and although they have met some pushback, they are still able to be active in Australia. Direct government backing of pro-vaccine groups is generally strong, though at arm's length, with some uncertainty over involvement with the activities of groups acting outside of conventional institutional channels. Governments prefer publics to reach broad social consensus on controversial topics (Irwin, 2006). Australia, at present, is seeing vaccine promotion crossing the major party lines, with a pro-vaccine media able to influence public policy and political rhetoric. 


\section{The motivation}

Thirdly, who is motivated to pursue these messages and why? The characteristics of activists not only shape the type of campaign pursued but can reveal their understanding of what it means to be pro-vaccine in their reasoning and objectives. Vaccinate California mainly identify as parents - not unexpected for an issue that typically concerns parents and especially mothers who often take greater responsibility for children's health (Ranji and Salganicoff, 2014), but compares with SAVN who mainly see themselves as science supporters. The reason behind why certain types of activists have appeared in Australia compared to the US appears to be related to what existing groups were in place and whether they were able to quickly reorganise to fill a gap for a pro-vaccine entity.

What has motivated these pro-vaccine activist groups to have an impact now? Two reasons present themselves: first, the threat of illness and death from what are thought to be vaccinepreventable diseases; and second, a perceived need to counter vaccine-critical views. Just as vaccine-critical groups mobilise on the basis of perceived harm to children, so do pro-vaccine activists for perceived harm caused by those who do not vaccinate rather than the vaccine. The trigger for both activist groups was child mortality or threat thereof, connected to low vaccination rates. This remains a motivating factor for supporters of vaccination to step out of the silent majority and become activists. A need to counter vaccine-critics is another motivating factor whether in the treatment of grieving parents, or their dominance in a community outbreak. The fact that many SAVN supporters are similarly supportive of other pro-science issues and countering pseudo-science claims demonstrates that countering vaccine-critics is also an act of addressing and penalising views deemed unacceptable in society.

\section{Conclusion}

Active support for vaccination through pro-vaccine activism relies on high-profile events as triggers and the provocation to fundamental beliefs concerning, on the one hand the value of science, evidence, and the state; and on the other a collective view of child-rearing or care for children. When not given enough reason to act, the pro-vaccine contingent of civil society remains inactive. Pro-vaccine activity results from triggers in media coverage and perception 
of a larger population affected by vaccine-preventable diseases. However, it is also a longerterm build-up of counter-mainstream views, profiled in public discourses and media representation, that eventually becomes unacceptable to mainstream publics.

Investigating this elusive pro-vaccine side is important to understand vaccination views and behaviours as a whole. This paper has concentrated on analysing the pro-vaccine civil society contingent, and the considered activist groups exemplify how activism can take different forms: grassroots-led, publicly confrontational activism in Australia, or issue-specific, nonconfrontational political activism in America. The form eventually taken has depended on local constraints on what has been feasible within organisational structures and where institutional support has been found.

Nevertheless, overall outcomes sought by the pro-vaccine activist groups are similar in that they both push policy and societal change towards more coercive measures to support vaccination. Previous activism or advocacy in civil society has been, on the whole, more information- and education-based. As Attwell and Smith (2017) argue, coercion may be problematic if hard-line policies create tiers of citizenship where vaccine decisions become a marker of identity. The concern is that views critical or wary of vaccination are neglected, and their proponents viewed as less worthy citizens. This disregard threatens the relationship of trust between parents and the state, with the potential for a larger backlash in the future.

Future studies could fruitfully adopt a symmetrical approach as a methodological heuristic in attention to unproblematised aspects of the vaccination debate. Such an approach can be taken further - for example, to the roles of various actors in vaccination debates and discourses, such as outliers of the medical establishment, health authorities, and governments critical of vaccination. Analogous activist groups and activities for alternative issues may arise in reaction to the greater perceived threat of counter-mainstream views gaining more prominence. The 'March for Science', for instance, which began in 2017, organises rallies and marches worldwide to celebrate science in the face of funding cutbacks and downgraded policy importance. Another parallel is that of counter-activism within polarised debates seeking 
government and public support, for example pro-choice groups getting "public space protection orders" to prevent harassment by anti-abortion protesters outside clinics in the UK (BBC News, 2018).

There are many other issue areas where a consideration of the 'pro-' side of binary distinctions can provide better explanations of public participatory dynamics, when reinforcement of the mainstream is not a well explored position within the health social movement literature. While public health authorities are, of course, highly concerned with 'problem publics' such as parents who do not vaccinate, it is also important to understand the parents who do vaccinate, and how to work alongside supportive civil society groups. Comparisons to other countries outside of an Anglo-centric view would be beneficial in this regard, as well as combining qualitative and quantitative methods. There is a wealth of data on vaccine uptake and attitudes that could further inform cross-country comparisons, and such research would be a welcome addition to the wider social movement and activism literature.

\section{References}

Attwell, K., \& Smith, D. T. (2017). Parenting as politics: social identity theory and vaccine hesitant communities. International Journal of Health Governance, 22(3), 183-198. https://doi.org/10.1108/lJHG-03-2017-0008

BBC News. (2018). Council backs move to stop anti-abortion "harassment" - BBC News. Retrieved July 4, 2018, from https://www.bbc.co.uk/news/uk-england-manchester-42804751

Beard, F. H., Leask, J., \& McIntyre, P. B. (2017). No Jab, No Pay and vaccine refusal in Australia: the jury is out. The Medical Journal of Australia, 206(9), 381-383. https://doi.org/10.5694/mja16.00944

Benford, R. D. (1993). "You Could be the Hundredth Monkey": Collective Action Frames and Vocabularies of Motive Within the Nuclear Disarmament Movement. The Sociological Quarterly, 34(2), 195-216. https://doi.org/10.1111/j.1533-8525.1993.tb00387.x

Bloor, D. (1991). Knowledge and social imagery. University of Chicago Press.

Blume, S. (2006). Anti-vaccination movements and their interpretations. Social Science \& Medicine, 62(3), 628-642. https://doi.org/10.1016/j.socscimed.2005.06.020

Bramwell, N. (2014). Not qualified to speak out? Retrieved November 29, 2017, from https://www.medicalobserver.com.au/professional-news/not-qualified-to-speak-out

Brown, P., \& Zavestoski, S. (2004). Social movements in health: An introduction. Sociology of Health and IIIness, 26(6), 679-694. https://doi.org/10.1111/j.0141-9889.2004.00413.x

Brown, P., Zavestoski, S., McCormick, S., Mayer, B., Morello-Frosch, R., \& Gasior Altman, R. (2004). Embodied health movements: new approaches to social movements in health. Sociology of Health and IIIness, 26(1), 5080. https://doi.org/10.1111/j.1467-9566.2004.00378.x

DiResta, R. (2017). This Dramatic Graph Shows How the Pro-Vaccine Movement Can Win. Slate. Retrieved from http://www.slate.com/articles/health_and_science/medical_examiner/2017/04/this_dramatic_graph_shows_ho w_the_pro_vaccine_movement_can_win.html

Dubé, E., Laberge, C., Guay, M., Bramadat, P., Roy, R., \& Bettinger, J. A. (2013). Vaccine hesitancy. Http://Dx.Doi.Org/10.4161/Hv.24657.

Dunlop, R. (2013a). A view on: vaccination myths. Retrieved July 16, 2017, from https://theconversation.com/a-viewon-vaccination-myths-14699

Dunlop, R. (2013b). Anti-vaccination activists should not be given a say in the media. The Guardian, p. 35. Retrieved from https://www.theguardian.com/commentisfree/2013/oct/16/anti-vaccination-activists-should-not-be-givena-say-in-the-media

Durbach, N. (2004). Bodily matters: The anti-vaccination movement in England, 1853-1907. Duke University Press. Retrieved from https://books.google.co.uk/books/about/Bodily_Matters.html?id=cphJifOrs2AC\&redir_esc=y

Ellerton, P. (2014). The problem of false balance when reporting on science. The Conversation. Retrieved from https://theconversation.com/the-problem-of-false-balance-when-reporting-on-science-29077

Faasse, K., Chatman, C. J., \& Martin, L. R. (2016). A comparison of language use in pro- and anti-vaccination comments in response to a high profile Facebook post,. Vaccine, 34(47), 5808-5814. https://doi.org/10.1016/j.vaccine.2016.09.029 
Goodwin, J., Jasper, J. M., Ferree, M. M., Flacks, R., Ganz, M., Goodwin, J., ... Tilly, C. (2003). Rethinking Social Movements: Structure, Meaning, and Emotion. Rowman \& Littlefield Publishers.

Grant, L., Hausman, B. L., Cashion, M., Lucchesi, N., Patel, K., \& Roberts, J. (2015). Vaccination persuasion online: a qualitative study of two provaccine and two vaccine-skeptical websites. Journal of Medical Internet Research, 17(5), e133. https://doi.org/10.2196/jmir.4153

Hajer, M. A. (2009). Authoritative governance: policy-making in the age of mediatization. Oxford University Press.

Hansen, J. (2013a). Grieving parents speak out against anti-vaccination extremists. Retrieved July 16, 2017, from http://www.dailytelegraph.com.au/news/opinion/grieving-parents-speak-out-against-anti-vaccinationextremists/news-story/2b0a81b5b3f391f42903bfb52851d7df

Hansen, J. (2013b). No jab, no play campaign launched to ban unvaccinated kids from childcare centres and preschools. Retrieved June 8, 2018, from https://www.dailytelegraph.com.au/news/national/no-jab-no-playcampaign-launched-to-ban-unvaccinated-kids-from-childcare-centres-and-preschools/newsstory/7fc848cff24a95927c94cadc927f77b7

Health Care Complaints Commission. (2014). Public statement - warning about the Australian Vaccination-skeptics Network, Inc. ('AVN'), formerly known as Australian Vaccination Network Inc. Retrieved May 27, 2018, from http://www.hccc.nsw.gov.au/Hearings---decisions/Public-statements-and-warnings/Public-statement--warning-about-the-Australian-Vaccination-skeptics-Network--Inc---AVN----formerly-known-as-AustralianVaccination-Network-Inc-

Healy, J., \& Paulson, M. (n.d.). Vaccine Critics Turn Defensive Over Measles. Retrieved July 15, 2017, from https://www.nytimes.com/2015/01/31/us/vaccine-critics-turn-defensive-over-measles.html

Hobson-West, P. (2007). 'Trusting blindly can be the biggest risk of all': organised resistance to childhood vaccination in the UK. Sociology of Health \& Illness, 29(2), 198-215. https://doi.org/10.1111/j.1467-9566.2007.00544.x

Irwin, A. (2006). The Politics of Talk: Coming to Terms with the 'New' Scientific Governance. Social Studies of Science, 36(2), 299-320. https://doi.org/10.1177/0306312706053350

Jacobs, C. (2015). Jonas Salk: A life.

Johnston, R. D. (2004). The politics of healing: Histories of alternative medicine in twentieth-century North America. Routledge.

Karafillakis, E., Larson, H. J., \& ADVANCE consortium. (2017). The benefit of the doubt or doubts over benefits? A systematic literature review of perceived risks of vaccines in European populations. Vaccine, 35(37), 48404850. https://doi.org/10.1016/..vaccine.2017.07.061

Kata, A. (2012). Anti-vaccine activists, Web 2.0, and the postmodern paradigm - An overview of tactics and tropes used online by the anti-vaccination movement. Vaccine, 30(25), 3778-3789. https://doi.org/10.1016/j.vaccine.2011.11.112

Khimm, S. (2010). Did the Anti-Vaccine Movement Help Create a Whooping Cough Epidemic? Retrieved October 13, 2017, from http://www.motherjones.com/kevin-drum/2010/06/vaccines-california-whooping-cough-epidemic/

Kuran, T. (1995). Private truths, public lies: The social consequences of preference falsification. Harvard University Press.

Leach, M., \& Fairhead, J. (2007). Vaccine anxieties: global science, child health and society. Earthscan.

Leask, J., \& Danchin, M. (2017). Imposing penalties for vaccine rejection requires strong scrutiny. Journal of Paediatrics and Child Health, 53(5), 439-444. https://doi.org/10.1111/jpc.13472

Loxton, D. (n.d.). Modern Skepticism's Unique Mandate. Retrieved August 7, 2017, from http://www.skepticblog.org/2013/05/13/modern-skepticisms-unique-mandate/

Martin, B. (2016). An Experience with Vaccination Gatekeepers, Brian Martin. Social Epistemology Review and Reply Collective, 5(10), 27-33.

McCarthy, J. D., \& Zald, M. N. (1977). Resource Mobilization and Social Movements: A Partial Theory. American Journal of Sociology. The University of Chicago Press. https://doi.org/10.2307/2777934

McInerney, F. (2000). Requested death: a new social movement. Social Science \& Medicine, 50(1), 137-154. https://doi.org/10.1016/S0277-936(99)00273-7

McNeil, D. G. (2009). Book Is Rallying Resistance to the Antivaccine Crusade. Retrieved October 10, 2017, from http://www.nytimes.com/2009/01/13/health/13auti.html

Meryl Dorey. (n.d.). Why I did what I did - why I do what I do by Meryl Dorey. Retrieved July 16, 2017, from http://www.whale.to/vaccine/dorey.html

Milken Institute School of Public Health. (2015). Q\&A with Tara Haelle: Time to Overhaul How We Talk About Health. Retrieved October 13, 2017, from https://mha.gwu.edu/blog/niam-2015-tara-haelle-interview/

Moskalenko, S., \& McCauley, C. (2009). Measuring Political Mobilization: The Distinction Between Activism and Radicalism. Terrorism and Political Violence, 21(2), 239-260. https://doi.org/10.1080/09546550902765508

Nichter, M. (1995). Vaccinations in the third world: A consideration of community demand. Social Science \& Medicine, 41(5), 617-632. https://doi.org/10.1016/0277-9536(95)00034-5

No Compulsory Vaccination. (n.d.). A Grieving Family and Baseless Accusations. Retrieved May 28, 2018, from http://nocompulsoryvaccination.com/2010/07/30/a-grieving-family-and-baseless-accusations/

Orenstein, W. A., \& Hinman, A. R. (1999). The immunization system in the United States - The role of school immunization laws. Vaccine, 17, S19-S24. https://doi.org/10.1016/S0264-410X(99)00290-X

Ranji, U., \& Salganicoff, A. (2014). Data Note: Balancing on Shaky Ground: Women, Work and Family Health I The Henry J. Kaiser Family Foundation. Retrieved September 19, 2017, from http://www.kff.org/privateinsurance/issue-brief/data-note-balancing-on-shaky-ground-women-work-and-family-health/

Reich, J. A. (2016). Calling the shots: Why parents reject vaccines. Retrieved from https://nyupress.org/books/9781479812790/

Ritzer, G. (2016). Essentials of sociology.

Scott, P., Richards, E., \& Martin, B. (1990). Captives of Controversy: The Myth of the Neutral Social Researcher in Contemporary Scientific Controversies. Science, Technology, \& Human Values, 15(4), 474-494. https://doi.org/10.1177/016224399001500406

Silver, I. (1997). Constructing "Social Change" through Philanthropy: Boundary Framing and the Articulation of Vocabularies of Motives for Social Movement Participation. Sociological Inquiry, 67(4), 488-503. https://doi.org/10.1111/j.1475-682X.1997.tb00449.x

Sisson, P. (2016). Lawyers pull San Diego lawsuit against California's controversial vaccination law. Retrieved 
October 11, 2017, from http://www.sandiegouniontribune.com/news/health/sdut-vaccine-lawsuit-sd-pulled2016sep01-story.html

Smallwood, C. (2008). Back Talk: Paul Offit. Retrieved May 18, 2018, from https://www.thenation.com/article/backtalk-paul-offit/

Spier, R. E. (2001). Perception of risk of vaccine adverse events: a historical perspective. Vaccine, 20, S78-S84. https://doi.org/10.1016/S0264-410X(01)00306-1

Thomas, R. J., Tandoc, E. C., \& Hinnant, A. (2017). False Balance in Public Health Reporting? Michele Bachmann, the HPV Vaccine, and "Mental Retardation." Health Communication, 32(2), 152-160. https://doi.org/10.1080/10410236.2015.1110006

Vaccinate California. (n.d.). Vaccinate California webpage. Retrieved July 16, 2017, from http://vaccinatecalifornia.org/

Venkatraman, A., Garg, N., \& Kumar, N. (2015). Greater freedom of speech on Web 2.0 correlates with dominance of views linking vaccines to autism. Vaccine, 33(12), 1422-1425. https://doi.org/10.1016/j.vaccine.2015.01.078

Ward, J. K. (2016). Rethinking the antivaccine movement concept: A case study of public criticism of the swine flu vaccine's safety in France. Social Science \& Medicine, 159, 48-57. https://doi.org/10.1016/J.SOCSCIMED.2016.05.003

Whatthefolly. (2015). Transcript: Mother \& Pro-Vaccination Advocate Leah Russin's testimony on SB 277 before the Senate Judiciary Committee - April 28, 2015. Retrieved June 23, 2017, from http://www.whatthefolly.com/2015/04/30/transcript-mother-pro-vaccination-advocate-leah-russins-testimonyon-sb-277-before-the-senate-judiciary-committee-april-28-2015/

Wilson, J. (1973). Introduction to social movements. Basic Books.

www.change.org. (n.d.). Eliminate the "personal belief" vaccine exemption that's putting sick California kids at risk. Retrieved June 23, 2017, from https://www.change.org/p/california-governor-eliminate-the-personal-beliefvaccine-exemption-that-s-putting-sick-california-kids-at-risk

Yaqub, O., Castle-Clarke, S., Sevdalis, N., \& Chataway, J. (2014). Attitudes to vaccination: A critical review. Social Science \& Medicine, 112, 1-11. https://doi.org/10.1016/j.socscimed.2014.04.018

\section{Appendix 1.}

\section{Table of interviewees by organisation type}

\begin{tabular}{|c|c|c|}
\hline & Case 1: Vaccinate California & Case 2: Stop the AVN (SAVN) \\
\hline Activist group & - $\quad$ Founders/members & - $\quad$ Founders/members \\
\hline $\begin{array}{l}\text { Health } \\
\text { authorities }\end{array}$ & $\begin{array}{l}\text { - Local and national health } \\
\text { authorities }\end{array}$ & Local health authorities \\
\hline $\begin{array}{l}\text { University } \\
\text { academics }\end{array}$ & $\begin{array}{l}\text { - Law, Health } \\
\text { Communication, History }\end{array}$ & - $\quad$ Philosophy, Sociology \\
\hline $\begin{array}{l}\text { High profile / } \\
\text { other } \\
\text { vaccination } \\
\text { supporters }\end{array}$ & $\begin{array}{l}\text { - } \text { NGOs } \\
\text { - Professional associations } \\
\text { - Paul Offit }\end{array}$ & $\begin{array}{ll} & \text { NGOs } \\
\text { - } & \text { New Zealand SAVN } \\
\text { supporters }\end{array}$ \\
\hline
\end{tabular}

\section{Appendix 2.}

\section{Interview guide - pro-vaccine activist groups}

Pro-vaccine views

1. Do you see yourself as a 'pro-vaccine activist'?

2. How would you describe your position on vaccination if you had to give it a name?

3. Have you come across other people or groups that characterize themselves as pro- 
vaccine? In what ways?

4. Who is responsible for ensuring parents vaccinate their children?

5. What sort of opposition have you faced?

6. How have you formed your views about vaccination?

7. How have your views on vaccination changed over time?

8. How do those around you feel about vaccination? Do any views greatly differ from yours and why?

Role and activities

9. How did you become involved with the group or pro-vaccine activities supportive of vaccination more generally? How long have you been involved?

10. How did everyone become connected and structure your activities?

11. What was the impetus for beginning?

12. Do you think your organisation has been a success?

13. How has support for opposing groups/views changed?

14. What methods/tactics/strategies have you used?

15. What sort of online activities have been undertaken?

Societal implications

16. How have you influenced how vaccination is addressed?

17. Where is the line between allowing harassment and censoring free speech?

18. Who supported you/is on your side and who continues to support you?

19. Are you pleased with the result? Is there anything you would change?

20. Is there anything you would have done differently?

21. What further work needs to be done now?

22. What are the goals of your organisation going forward?

Country context

23. What is the current state of vaccination attitudes and take-up?

24. Do you think there are differences in vaccination policy at a local level compared with the national level?

25. How is vaccination portrayed in the media?

26. What has been the reception of the current government and media? 
27. Who do you think promotes pro-vaccine views and how?

28. Do you think your work could be replicated elsewhere? 